\title{
Workplace Flexibility, Work Hours, and Work-Life Conflict: Finding an Extra Day or Two
}

\author{
E. Jeffrey Hill \\ Brigham Young University - Provo, jeff_hill@byu.edu \\ Jenet Jacob Erickson \\ Brigham Young University - Provo \\ Erin K. Holmes \\ Brigham Young University - Provo \\ Maria Ferris \\ IBM Global Workforce Diversity
}

Follow this and additional works at: https://scholarsarchive.byu.edu/facpub

Part of the Other Social and Behavioral Sciences Commons

\section{Original Publication Citation}

Hill, E. J., Erickson, J. J., Holmes, E. K., \& Ferris, M. (2010). Workplace flexibility, work hours, and work-life conflict: An extra day or two. Journal of Family Psychology, 24(3), 349-358.

\section{BYU ScholarsArchive Citation}

Hill, E. Jeffrey; Erickson, Jenet Jacob; Holmes, Erin K.; and Ferris, Maria, "Workplace Flexibility, Work Hours, and Work-Life Conflict: Finding an Extra Day or Two" (2010). Faculty Publications. 4041.

https://scholarsarchive.byu.edu/facpub/4041

This Peer-Reviewed Article is brought to you for free and open access by BYU ScholarsArchive. It has been accepted for inclusion in Faculty Publications by an authorized administrator of BYU ScholarsArchive. For more information, please contact ellen_amatangelo@byu.edu. 


\title{
Workplace Flexibility, Work Hours, and Work-Life Conflict: Finding an Extra Day or Two
}

\author{
E. Jeffrey Hill, Jenet Jacob Erickson, and \\ Erin K. Holmes \\ Brigham Young University
}

\author{
Maria Ferris \\ IBM Global Workforce Diversity
}

\begin{abstract}
This study explores the influence of workplace flexibility on work-life conflict for a global sample of workers from four groups of countries. Data are from the 2007 International Business Machines Global Work and Life Issues Survey administered in 75 countries $(N=$ 24,436). We specifically examine flexibility in where (work-at-home) and when (perceived schedule flexibility) workers engage in work-related tasks. Multivariate results indicate that work-at-home and perceived schedule flexibility are generally related to less work-life conflict. Break point analyses of sub-groups reveal that employees with workplace flexibility are able to work longer hours (often equivalent to one or two 8-hr days more per week) before reporting work-life conflict. The benefit of work-at-home is increased when combined with schedule flexibility. These findings were generally consistent across all four groups of countries, supporting the case that workplace flexibility is beneficial both to individuals (in the form of reduced work-life conflict) and to businesses (in the form of capacity for longer work hours). However, work-at-home appears less beneficial in countries with collectivist cultures.
\end{abstract}

Keywords: workplace flexibility, work hours, work-life conflict, telecommuting, flextime

Workplace flexibility has been identified as central to research on the work-life interface and a key strategy used by work-life policy makers in their attempt to cope with today's global economy (Hill \& Civian, 2008). Recent meta-analyses have demonstrated its association with reduced work-family conflict (Allen \& Shockley, 2009; Byron, 2005; Gajendran \& Harrison, 2007; MesmerMagnus \& Viswesvaran, 2006). However, these metaanalyses also indicate significant gaps. Findings are inconclusive about whether it is use of flexible work arrangements or the perception of the availability of flexibility that is associated with reduced work-life conflict (Jones et al., 2008). Further, most research has considered flexibility in when workers engage in work-related tasks (flextime, schedule flexibility, compressed work weeks, etc.) or where workers engage in work-related tasks (flex-

E. Jeffrey Hill, Jenet Jacob Erickson, and Erin K. Holmes, School of Family Life, Brigham Young University; Maria Ferris, IBM Global Workforce Diversity.

The authors would like to thank International Business Machines Corporation (IBM) for providing the support and cooperation needed to collect the data used in this article. Ideas expressed are the opinions of the authors, not necessarily of IBM. We also thank the Family Studies Center of the BYU School of Family Life for its support of this project. Finally, we thank our research assistant, Sarah June Carroll, for her valuable assistance throughout the preparation of this manuscript.

Correspondence concerning this article should be addressed to E. Jeffrey Hill, School of Family Life, Brigham Young University, 2052 JFSB, Provo, UT 84602. E-mail: jeff_hill@byu.edu place, telecommuting, virtual office, mobility, etc.) but have not explored how these types of flexibility interact together. In addition, the few multinational studies that have explored flexibility suggest that its influence differs across cultural contexts, but little is known about what these differences might be (Hill, Yang, Hawkins, \& Ferris, 2004).

This study fills these gaps. First, we explore the relationship of schedule flexibility, work-at-home, and the two together to work-life conflict. Second, we examine whether it is the use of flexibility (work-at-home) or simply availability of flexibility (perceived schedule flexibility) that produces benefits. Third, we compare these findings across four groups of countries representing a range of cultural contexts. Finally, we include implications for policymakers.

\section{Conceptual and Theoretical Framework}

Voydanoff's (2004) theoretical application of ecological systems theory (Bronfenbrenner, 1986) to the interface of work and life provides the conceptual framework for the current study. Ecological systems theory views work and life as discrete microsystems consisting of patterns of activities, roles, and relationships. The reciprocal influence between the microsystems of work and life compose what is called the work-life mesosystem. When the boundaries between these microsystems are permeable, characteristics associated with the work and life domains influence each other. Work-life conflict is identified as the linking mechanism through which work and life are related to one another and to individual and work outcomes. Work-life conflict consists of a cognitive appraisal of interrole conflict in 
which individuals feel that the demands of paid work and life roles are incompatible. Incompatibility is experienced as participation in either paid work or life roles is made more difficult because of the demands of the other role.

According to Voydanoff (2004), the appraisal of conflict depends on the relationship between an individual's resources and environmental demands. An appraisal of stress reflects a perception that the relationship between work and life is exceeding individual resources. Resources are "structural or psychological assets that may be used to facilitate performance, reduce demands or generate additional resources" (Voydanoff, 2004, p. 398). Flexibility in where (work-at-home) and when (perceived schedule flexibility) workers engage in work-related roles and responsibilities are explored as resources that may be used to facilitate performance, reduce demands, or generate resources in the work and life domains. Work-at-home may increase time resources by reducing commute time, and enable greater ability to meet life roles because of more face-to-face availability. Perceived schedule flexibility may enable more effective utilization of the temporal resources to be available to life roles at times of most benefit (e.g., flextime may enable a parent to participate in an afternoon school activity with a child).

This study defines workplace flexibility as "the ability of workers to make choices influencing when, where, and for how long they engage in work-related tasks" (Hill et al., 2008 , p. 152). We use the term work-life conflict to capture conflict representing incompatibility between work, personal life, and family life. Our definition slightly modifies Greenhaus and Beutell's (1985) definition of work-family conflict, "a form of inter-role conflict in which the role pressures from the work and [personal]/family life domains are mutually incompatible in some respect. That is, participation in work [personal]/family) roles is made more difficult by virtue of participation in the [personal]/family (work) roles" (p. 76).

To aid in understanding findings across four groups of countries representing a range of cultural contexts in the West and the East, we utilize theory developed by Hofstede (1980) who conducted surveys focused on work-related values of International Business Machines (IBM) employees in 39 countries. He differentiated cultures along four dimensions, including power distance, uncertainty avoidance, masculinity/femininity, and individualism versus collectivism. This last dimension has proven to be useful in categorizing cultures for cross-national research comparisons. In their seminal meta-analysis of individualism and collectivism Oyserman, Coon, \& Kemmelmeier (2002) identified 253 studies structured along this dimension. We have chosen to use individualism and collectivism as the framework to organize the multi-national comparisons in the present study.

Individualism is grounded in "the assumption that individuals are independent of one another" (Oyserman et al., 2002, p. 4). Hoftstede proposed that individualistic cultures such as the United States and other countries of the West are self-oriented and value personal time, freedom, and challenge. Within individualistic cultures workplace flexibility would likely be seen as a means to create a work environment more in harmony with "a concern for oneself and immediate family, an emphasis on personal autonomy and self-fulfillment, and the basing of one's identity on one's personal accomplishments" (Oyserman et al., 2002, p. 4). By comparison, collectivism is grounded in "the assumption that groups bind and mutually obligate individuals" (Oyserman et al., 2002, p. 5). Hofstede (1980) noted that in the collectivist cultures of the East individuals are intrinsically connected through strong personal ties based on loyalty to the group and on family ties. In such cultural orientations, workplace flexibility may not be valued as highly because it may hinder the group ethic. For example, work-at-home might be eschewed because it would reduce the amount of face-to-face group interaction.

\section{Literature Review}

This study's examination of the relationship of workplace flexibility (work-at-home and perceived schedule flexibility) and work hours to work-life conflict is informed by previous research in the following areas: (a) work hours, work-at-home, schedule flexibility, and work-life conflict; (b) used workplace flexibility versus perceived availability of workplace flexibility; and (c) global comparisons of workplace flexibility analyses.

\section{Work Hours, Work-at-Home, Schedule Flexibility, and Work-Life Conflict}

A plethora of studies have found that work hours are associated with greater work-family conflict and that workplace flexibility is associated with less work-family conflict. However, there are many different mediators and moderators of these relationships (Jacob, Allen, Hill, \& Mead, 2008). Using a sample from the UK, Hughes and Parkes (2007) found that paid work hours was a significant predictor of greater work-family interference, but that this relationship was moderated by schedule flexibility. Judge, Boudreau, and Bretz (1994) found a strong relationship between the number of paid work hours and work/family conflict, especially for those with preschool children. Shockley and Allen (2007) found that work hours was positively associated with greater work interference with family life in all of their models. In an interesting twist, Jacob et al. (2008) found that the frequency of missed evening family meals because of work mediated the negative relationship between long work hours and work-family conflict as well as a variety of and work and family outcomes. That is, work hours only predicted work-family conflict when the employee missed family mealtime.

Three recent meta-analytic reviews have examined the relationship of workplace flexibility (in time and place) and work-family conflict. Byron's (2005) meta-analysis utilizing eight studies found that schedule flexibility was significantly associated with less work-family conflict. The metaanalytic effect size was -.30 for the relationship between schedule flexibility and work-interference with family and -.17 for the relationship between schedule flexibility and 
family interference with work. Gajendran and Harrison's (2007) meta-analysis utilizing 19 studies found telecommuting was related to less work-family conflict with a metaanalytic effect size of -.13 . They also found that highintensity, but not low-intensity telecommuting was related to less work-family conflict. In contrast, Mesmer-Magnus and Viswesvaran's (2006) meta-analysis using five studies found no significant relationship among the presence of flexibility programs (both time and place) and work-tofamily and family-to-work conflict. In explaining the inconsistencies, Allen and Shockley (2009) emphasized the importance of distinguishing the use of flexible arrangements from the availability of those arrangements.

Hughes and Parkes (2007) found that schedule flexibility moderated the relationship between work hours and workfamily conflict. Shockley and Allen (2007) also found that flextime was significantly correlated with less work interference but flexplace was not. These findings were consistent with analyses using a global sample of IBM employees that found that perceived flexibility was related to lower work-life conflict (Hill et al., 2004).

\section{Used Workplace Flexibility versus Perceived Availability of Workplace Flexibility}

While many studies document that workplace flexibility decreases work-family conflict, some question whether employees must actually use flexible work arrangements, or whether the perception of availability would be sufficient to produce this effect. Using data from Singapore, Jones et al. (2008) found perceived workplace flexibility to be significantly related to work-family fit; used workplace flexibility was not. They concluded, "actually using workplace flexibility is not a prerequisite to achieve these outcomes [positive benefits]. Indeed, just the perception that the flexibility would be available when needed appears to be sufficient" (Jones et al., 2008, p. 781). Grzywacz, Carlson, and Shulkin (2008) also found positive associations of using flextime to be mediated by perceived flexibility. No other studies were found in this area.

\section{Multi-National Comparisons of Workplace Flexibility Analyses}

There has been little research examining workplace flexibility using a global sample, or comparing groups of countries. Hill et al. (2004) found that job flexibility was related to lower work-family conflict in a 48-country global sample. When the sample was divided into four groups this relationship was true of those in the East, in the WestDeveloping, and in the United States. However, job flexibility was related to greater work-family conflict in the West Affluent (basically Western Europe and Australia). Their study used a global measure of perception of job flexibility and did not distinguish between when and where workers engaged in work-activities.

\section{Hypotheses and Research Question}

The gap in global research in combination with our conceptual framework and literature review facilitated development of the following hypotheses: (a) work hours will be positively associated with work-life conflict after controlling for age, sex, and having a child age 5 years or younger; (b) workplace flexibility (work-at-home, schedule flexibility, and work-at-home combined with schedule flexibility) will be negatively associated with work-life conflict after controlling for work hours, sex, and having a child age 5 years or younger; (c) schedule flexibility (perceived workplace flexibility) will be more strongly associated with reduced work-life conflict than work-at-home (used workplace flexibility) after controlling for age, sex, and having a child age 5 years or younger; and (d) workplace flexibility will be poorly utilized and not associated with lower worklife conflict for those in countries with collectivist cultures. We also examine the research question: how do these results vary in different cultures of the world?

\section{Method}

\section{Data Collection and Sample}

The 2007 IBM Global Work and Life Issues Survey was administered in 75 countries with 59,052 invitees and 24,436 respondents for a response rate of $41 \%$. A random sample of IBM employees around the world was selected and stratified by sex and by country to assure sufficient responses for statistically reliable results by sex and by country. IBM's policy is to staff their international operations with local talent that is reflective of the diversity within each country and rarely with employees from the United States. To accommodate the wide array of local cultures the questionnaire was translated into 10 different languages. Preliminary translations were carefully reviewed and edited by human resources personnel in each area of the world to assure that the translations accurately carried the intended meanings related to this sensitive topic. Altogether $17 \%$ of the IBM global population was invited to take the survey.

The overall sample was 52\% men and $48 \%$ women with an average age of 41 , an average tenure with IBM of 11 years, and an average of .88 children. The sample represented the distribution of job levels among IBM employees: professionals (83\%), managers (15\%), and executives (3\%). The types of jobs reported were indicative of the high level of skills needed: information/technology professionals (28\%), sales/marketing (22\%), hardware/software/other engineers $(11 \%)$, customer/product support (9\%), consultants $(8 \%)$, administration $(5 \%)$, manufacturing $(1 \%)$, and other job categories $(15 \%)$. These jobs typically require high levels of university education and are generally compensated with above-average salaries.

The 75 countries were divided into four culturally related groups using rationale informed by Hofstede (2001). East included 14 countries with collectivist cultures, all in Asia. West-Developing included 31 countries with individualistic 
cultures with a per capita GDP less than $\$$ US 20,000 per year. West Affluent included 29 countries with individualistic cultures with a per capita GDP greater than \$US 20,000 per year. West-US comprised just the United States because it is unique in being an affluent, individualistic country with limited governmental work and family intervention.

\section{Measurement}

The dependent variable, work-life conflict, was measured by a single item, "How easy or difficult is it for you to manage the demands of your work and your personal/family life?" $(1=$ very easy, $2=$ easy, $3=$ neither easy nor difficult, $4=$ difficult, $5=$ very difficult). We were not able to used established multi-item work-life conflict scales because IBM limited the number of questions that could be asked to reduce the time required to take the survey. Though this may be seen as a limitation, research has shown that the use of single-item measures may yield reliable results (see Wanous, Reichers, \& Hudy, 1997; and Zimmerman et al., 2006).

The primary independent variables measuring workplace flexibility were work-at-home, schedule flexibility, and work hours. Work-at-home was a dichotomous variable identifying those who responded "at home" when asked, "Which of the following best describes where you do most of your IBM work?" Work-at-home referred to those who chose to complete most of their IBM work at home and did not include those who worked from only home occasionally. Virtually all IBM employees who work primarily at home do so because they choose to, not because IBM requires them to do so. In addition, almost all work-at-home employees have the flexibility to work in shared offices at an IBM location when it is advantageous to do so. Schedule flexibility was measured by the question, "How much flexibility (personal control) do you have in scheduling WHEN you do your work (scheduling the hours you work, the time of day, etc.). Responses ranged from $(1=$ no flexibility to $5=$ complete flexibility). Work hours was measured by the question, "How many hours per week do you TYPICALLY work for IBM? (Please make an average per week estimate covering the last 6 months). Control variables included Child $<5$ (at least one dependent child 5 years of age or younger), Sex (female or male), and Age (respondent's age in years). These were included because they are often associated with work-life conflict (Hill, Grzywacz, et al., 2008).

\section{Plan for Analyses}

Ordinary least square (OLS) regression analyses were conducted to determine the degree to which work-at-home and schedule flexibility predicted work-life conflict beyond work hours, having a child age 5 and younger, sex, and age. Models of these predictors were run for each of five groups (Global, East, West developing, West Affluent, and United States). The first model regressed work-life conflict on age, sex, child $<5$ years, and work hours. The second model added work-at-home and the third model added schedule flexibility.

To demonstrate the personal benefit of workplace flexibility to policy makers (who often do not have extensive training in regression analyses), we compared the percentages of a variety of groups who indicated they were having a difficult or very difficult time balancing the demands of their work and family life given a reasonable workload. We compared those who worked primarily from home (workat-home: yes) with those who did not (work-at-home: no); we compared those who reported complete or a great deal of schedule flexibility (high flexibility) with those who reported no or little schedule flexibility (low flexibility); and then we compared those who did work-at-home and reported high flexibility with those who did not work-at-home and reported low flexibility. For those who indicated they worked 40 to $50 \mathrm{hr}$ per week (a work week we considered to be of reasonable hours), we calculated the percentage who reported work-family difficulty.

To demonstrate the business benefit of perceived job flexibility in terms used by policy makers, a break point analysis was designed (modification of Hill, Hawkins, Ferris, \& Weitzman, 2001). The break point was defined as the statistical point in the number of weekly work hours at which $25 \%$ of the sample responded they had a difficult or very difficult time managing the demands of their work and personal/family life. The break point figures were calculated by regressing work-life conflict as a dichotomous variable $(1=$ very difficult or difficult; $0=$ very easy, easy, or neither easy nor difficult) on work hours. We calculated the break point for various groups by setting work-life conflict equal to .25 and solved for work hours. We calculated the break point for those working primarily at home versus those who were not, those with high schedule flexibility versus those with low schedule flexibility, and those who both worked primarily from home and reported high schedule flexibility versus those not working primarily from home and who reported low schedule flexibility. This approximates an interactive effect of work-at-home $\times$ schedule flexibility. To verify the statistical significance of the interaction we included this interaction term in the original regression equation. It was significant, $\beta=-.096, p<$ .001 .

\section{Results}

Means, $S D$ s, and correlations among all variables are presented in Table 1. Descriptive statistics (see Table 2) revealed that about one third (31\%) of employees reported work-life conflict. Those in the East were most likely to report difficulty (37\%). Those in the West Affluent were the least (30\%). Those who worked primarily from home varied considerably, ranging from $31 \%$ in the United States to $2 \%$ in the East, with a global average of $15 \%$. Overall, $36 \%$ reported high schedule flexibility, ranging from 38\% in West Affluent to $31 \%$ in West Developing. The number of weekly work hours fell within a narrow range between $47 \mathrm{hr}$ per week in West Affluent and $51 \mathrm{hr}$ per week in the United States. Work hours were significantly and positively corre- 
Table 1

Means, SDs, and Correlations Among All Study Variables

\begin{tabular}{|c|c|c|c|c|c|c|c|c|}
\hline Variable & Means & $S D$ & $\begin{array}{l}\text { Work-life } \\
\text { conflict }\end{array}$ & $\begin{array}{l}\text { Schedule } \\
\text { flexibility }\end{array}$ & $\begin{array}{c}\text { Work-at- } \\
\text { home }\end{array}$ & $\begin{array}{l}\text { Work } \\
\text { hours }\end{array}$ & Child $<5$ & Sex \\
\hline Work-life conflict $(1=$ least, $5=$ most $)$ & 3.00 & .945 & & & & & & \\
\hline Schedule flexibility $(1=$ least, $5=$ most $)$ & 3.11 & .974 & $-.307^{* * * *}$ & & & & & \\
\hline Work-at-home $(0=$ no, $1=$ yes $)$ & .14 & .356 & $-.102^{* * * *}$ & $.157^{* * * *}$ & & & & \\
\hline Work hours (per week) & 49.61 & 9.210 & $.336^{* * *}$ & $-.074^{* * * *}$ & $.021^{* * *}$ & & & \\
\hline Child $<5(0=$ no, $1=$ yes $)$ & .18 & .390 & $.070^{* * * * *}$ & $.024^{* * * *}$ & -.004 & $-.035^{\text {**** }}$ & & \\
\hline $\operatorname{Sex}(0=$ men, $1=$ women $)$ & .48 & .500 & $-.020^{* *}$ & -.006 & $.100^{* * * *}$ & $-.027^{* * * *}$ & $-.067^{* * * *}$ & \\
\hline Age (years) & 41.45 & 9.898 & $-.018^{* *}$ & $.063^{* * * *}$ & $.185^{* * * *}$ & $.056^{\text {**** }}$ & $-.215^{* * *}$ & $-.084^{* * * *}$ \\
\hline
\end{tabular}

${ }^{*} p<.05 . \quad{ }^{* *} p<.01 .{ }^{* * * *} p<.001$.

lated with work-life conflict. Workplace flexibility (both schedule flexibility and work-at-home) was significantly and negatively correlated with work-life conflict. Next, we examine the results organized around our hypotheses and research question, and then report analyses designed to make the results salient to policy makers.

Hypothesis 1 was supported. OLS regression analyses revealed that paid work hours had a significantly positive relationship to work-life conflict in all of the models, in every region. Work hours had the strongest relationship to work-life conflict of all the variables, ranging from $\beta=$ $.289, p<.001$ in the West Developing to $\beta=.383, p<$ .001 in the East (see Table 3).

Hypothesis 2 was generally supported. OLS regression analyses revealed that work-at-home was significantly and negatively associated with work-life conflict for almost all of the models and regions. However, after including schedule flexibility in the East, the relationship was no longer significant, $\beta=-.015, n s$. The strength of the relationship ranged from $\beta=-.015, n s$ in the East, to $\beta=-.110, p<$ .001 for the global sample and the United States. In addition, schedule flexibility was significantly and negatively associated with work-life conflict in all the models and regions of the world. The strength of the relationship ranged from $b=-.260$, in the West Affluent, to $\beta=-.317, p<$ .001 in the East.

Hypothesis 3 was supported. Schedule flexibility (perceived workplace flexibility) was a stronger predictor of work-life conflict than work-at-home (used workplace flexibility) (see Table 3, Model 3). That finding was consistent in the overall data (schedule flexibility, $\beta=-.277, p<$
.001 ; work-at-home, $\beta=-.066, p<.001$ ), in the East (schedule flexibility, $\beta=-.317, p<.001$; work-at-home, $\beta=-.015, n s$ ), in the West Developing (schedule flexibility, $\beta=-.284, p<.001$; work-at-home, $\beta=-.050$, $p<.01$ ), in the West Affluent (schedule flexibility, $\beta=$ $-.260, p<.001$; work-at-home, $\beta=-.057, p<.001$ ), and in the United States (schedule flexibility, $\beta=-.279, p<$ .001 ; work-at-home, $\beta=-.049, p<.001$ ).

Hypothesis 4 was partially supported. Employees in the East were the least likely to work from home ( 2 vs. $4 \%$ in West Developing, 8\% in West Affluent, and 33\% in the United States). In the final model, as predicted by the hypothesis, work-at-home was not significantly associated with work-life conflict: $(\beta=-.015, n s)$. However, schedule flexibility was associated with lower work-life conflict $(\beta=-.317, p<.001)$.

In response to Research Question 1, several other differences among the four regions of the global sample were revealed. In West Developing, West Affluent, and the United States, more advanced age positively predicted work-life conflict, but in the East it predicted less work-life conflict. In the East and West Affluent, females reported greater work-life conflict but in the United States females reported less. Having a dependent child age 5 years or younger and working more hours were associated with greater work-life conflict in all regions of the world. Workat-home predicted less work-life conflict in every region except the East. Finally, schedule flexibility was associated with less work-life conflict in every region. Other differences by areas of the world have been documented in the results supporting each of the hypotheses.

Table 2

Descriptive Statistics by World Region With Effect Sizes

\begin{tabular}{|c|c|c|c|c|c|c|c|c|c|}
\hline & Global & East & East ES* & West Dev & $\begin{array}{c}\text { West Dev } \\
\text { ES }^{*}\end{array}$ & $\begin{array}{c}\text { West } \\
\text { Affluent }\end{array}$ & $\begin{array}{l}\text { West Aff } \\
\text { ES }^{*}\end{array}$ & $\begin{array}{l}\text { United } \\
\text { States }\end{array}$ & $\begin{array}{c}\text { United States } \\
\text { ES }^{*}\end{array}$ \\
\hline Work-life conflict & 0.31 & 0.37 & 0.13 & 0.30 & -0.04 & 0.31 & -0.03 & 0.31 & -0.01 \\
\hline Schedule flexibility (\% high) & 0.35 & 0.30 & -0.11 & 0.31 & -0.11 & 0.38 & 0.09 & 0.36 & 0.02 \\
\hline Work-at-home (\% yes) & 0.15 & 0.02 & -0.60 & 0.04 & -0.46 & 0.08 & -0.35 & 0.31 & 0.77 \\
\hline Work hours (per week) & 49.59 & 52.28 & 0.32 & 49.62 & 0.00 & 47.10 & -0.42 & 50.84 & 0.22 \\
\hline Child $<5$ (\% yes) & 0.19 & 0.22 & 0.10 & 0.23 & 0.13 & 0.20 & 0.04 & 0.15 & -0.17 \\
\hline Gender (\% women) & 0.48 & 0.47 & -0.02 & 0.43 & -0.13 & 0.46 & -0.07 & 0.54 & 0.16 \\
\hline Age (years) & 41.48 & 36.35 & -0.65 & 35.86 & -0.71 & 41.69 & 0.03 & 45.80 & 0.68 \\
\hline
\end{tabular}

* Effect size determined for each region by calculating the difference in the region mean from the global mean without that region, and then dividing that difference by the average of the two $S D$ s. 
Table 3

Summary of OLS Regression Analyses On Work-Life Conflict Adding Work-at-Home and Schedule Flexibility $(N=21,469)$

\begin{tabular}{|c|c|c|c|c|c|c|c|c|c|c|}
\hline \multirow[b]{2}{*}{ Variable } & \multicolumn{2}{|c|}{$\begin{array}{c}\text { Global } \\
N=21,469\end{array}$} & \multicolumn{2}{|c|}{$\begin{array}{c}\text { East } \\
N=2,894\end{array}$} & \multicolumn{2}{|c|}{$\begin{array}{l}\text { West Developing } \\
\qquad N=3,662\end{array}$} & \multicolumn{2}{|c|}{$\begin{array}{l}\text { West Affluent } \\
N=7,120\end{array}$} & \multicolumn{2}{|c|}{$\begin{array}{l}\text { United States } \\
N=7,711\end{array}$} \\
\hline & $B$ & $S E \mathrm{~B}^{*}$ & $B$ & $S E \mathrm{~B}^{*}$ & $B$ & $S E \mathrm{~B}^{*}$ & $B$ & $S E \mathrm{~B}^{*}$ & $B$ & $S E \mathrm{~B}^{*}$ \\
\hline \multicolumn{11}{|l|}{ Model 1} \\
\hline Age & -.002 & $.001^{* * *}$ & -.008 & $.002^{* * * * *}$ & .000 & .002 & .001 & .001 & .002 & .001 \\
\hline Sex & -.008 & .012 & .095 & $.031^{* * *}$ & .015 & .029 & .040 & .021 & -.074 & $.021^{* * * * * *}$ \\
\hline Child $(<5$ years $)$ & .193 & $.016^{* * * *}$ & .167 & $.037^{* * * *}$ & .154 & $.034^{* * * *}$ & .259 & $.026^{* * * *}$ & .187 & $.034^{* * * *}$ \\
\hline Work hours & .035 & $.001^{* * * *}$ & .032 & $.001^{* * * *}$ & .030 & $.002^{* * * *}$ & .036 & $.001^{* * * * *}$ & .040 & $.001^{* * * *}$ \\
\hline$R^{2}$ & \multicolumn{2}{|c|}{.12} & \multicolumn{2}{|c|}{.16} & \multicolumn{2}{|c|}{$.10^{.002}$} & \multicolumn{2}{|c|}{$.12^{.011}$} & \multicolumn{2}{|c|}{.13} \\
\hline \multicolumn{11}{|l|}{ Model 2} \\
\hline Age & .000 & .001 & -.008 & $.002^{* * * *}$ & .001 & .002 & .002 & .001 & .003 & $.001^{* *}$ \\
\hline Sex & .018 & .012 & .097 & $.031^{* * *}$ & .024 & .029 & .053 & $.021^{*}$ & -.045 & $.021^{*}$ \\
\hline Child $(<5$ years $)$ & .206 & $.016^{* * * *}$ & .170 & $.037^{* * * * *}$ & .162 & $.034^{* * * *}$ & .269 & $.026^{* * * *}$ & .212 & $.032^{* * * *}$ \\
\hline Work hours & .035 & $.001^{* * * *}$ & .032 & $.001^{* * * * *}$ & .030 & $.002^{* * * * *}$ & .036 & $.001^{* * * *}$ & .040 & $.001^{* * * * * * *}$ \\
\hline Work-at-home & -.287 & $.017^{* * * *}$ & -.253 & $.116^{* * *}$ & -.368 & $.075^{* * * *}$ & -.307 & $.038^{* * * * *}$ & -.232 & $.023^{* * * *}$ \\
\hline$R^{2}$ & \multirow{2}{*}{\multicolumn{2}{|c|}{$\begin{array}{r}.13 \\
\Delta .01\end{array}$}} & \multirow{2}{*}{\multicolumn{2}{|c|}{$\begin{array}{r}.16 \\
\Delta .00\end{array}$}} & \multirow{2}{*}{\multicolumn{2}{|c|}{$\begin{array}{r}.10 \\
\Delta .00\end{array}$}} & \multirow{2}{*}{\multicolumn{2}{|c|}{$\begin{aligned} .13 \\
\Delta .01\end{aligned}$}} & \multirow{2}{*}{\multicolumn{2}{|c|}{$\begin{array}{r}.14 \\
\Delta .01\end{array}$}} \\
\hline$\Delta R^{2}$ & & & & & & & & & & \\
\hline \multicolumn{11}{|l|}{ Model 3} \\
\hline Age & .001 & $.001^{*}$ & -.004 & $.002^{*}$ & .003 & $.002^{*}$ & .003 & $.001^{* * *}$ & .003 & $.001^{*}$ \\
\hline $\operatorname{Sex}$ & .011 & .012 & .073 & $.030^{*}$ & .020 & .028 & .043 & $.020^{*}$ & -.041 & $.020^{*}$ \\
\hline Child ( $<5$ years) & .227 & $.015^{\text {**** }}$ & .164 & $.035^{\text {***** }}$ & .169 & $.032^{* * *}$ & .306 & $.025^{* * *}$ & .215 & $.030^{* * * *}$ \\
\hline Work hours & .033 & $.001^{* * * *}$ & .030 & $.001^{\text {**** }}$ & .029 & $.002^{* * * *}$ & .034 & $.001^{* * * *}$ & .038 & $.001^{* * * *}$ \\
\hline Work-at-home & -.172 & $.017^{* * * * *}$ & -.105 & .110 & -.283 & $.072^{* *}$ & -.195 & $.037^{* * * *}$ & -.103 & $.022^{* * * *}$ \\
\hline Schedule flexibility & -.268 & $.006^{* * * *}$ & -.280 & $.014^{* * * *}$ & -.250 & $.013^{* * * *}$ & -.256 & $.011^{* * * *}$ & -.289 & $.011^{* * * *}$ \\
\hline$R^{2}$ & \multirow{2}{*}{\multicolumn{2}{|c|}{$\begin{array}{r}.2 i^{000} \\
\Delta .08\end{array}$}} & \multicolumn{2}{|c|}{.25} & \multicolumn{2}{|c|}{$.18^{.010}$} & \multirow{2}{*}{\multicolumn{2}{|c|}{.19}} & \multirow{2}{*}{\multicolumn{2}{|c|}{$\begin{array}{r}.21 \\
\Delta .07\end{array}$}} \\
\hline$\Delta R^{2}$ & & & & & & & & & & \\
\hline
\end{tabular}

\section{Results of Analyses Designed for Policy Makers}

Given a work week of reasonable length (40 to $50 \mathrm{hr}$ ) fewer of those working from home reported difficulty with work-life conflict than those not working from home (see Table 4). In the global sample $15 \%$ of work-at-home employees reported work-life conflict compared to $22 \%$ of those not working primarily from home, a difference of $7 \%$. Only $23 \%$ of women with children age 5 years and younger who worked at home reported work-difficulty compared to $38 \%$ of those who did not work primarily from home. The differences were even more pronounced for those with high schedule flexibility. For example, in the global sample, those with high flexibility were only about one third as likely (13\%) to report work-life conflict compared to those with low flexibility (35\%). In West Developing only $9 \%$ of those with high flexibility reported difficulty compared to $33 \%$ of those with low flexibility. The most dramatic differences came by comparing work-at-home employees with high flexibility to nonwork-at-home employees with low flexibility. In the East, work-at-home, high-flex employees were only one sixth as likely to report work-life conflict as nonwork-athome, low-flex employees (6 vs. 36\%). The largest ab-

Table 4

Percentage of Respondents Reporting Work-Life Conflict (Moderate Work Hours)

\begin{tabular}{|c|c|c|c|c|c|c|c|c|c|}
\hline & \multicolumn{3}{|c|}{ Work-at-home } & \multicolumn{3}{|c|}{ Schedule flexibility } & \multicolumn{3}{|c|}{$\begin{array}{l}\text { Work-at-home and schedule } \\
\text { flexibility }\end{array}$} \\
\hline & Yes & No & $\Delta$ & High & Low & $\Delta$ & Both & Neither & $\Delta$ \\
\hline Global & $15 \%$ & $22 \%$ & $7 \%$ & $13 \%$ & $35 \%$ & $22 \%$ & $10 \%$ & $35 \%$ & $25 \%$ \\
\hline East & $12 \%$ & $23 \%$ & $11 \%$ & $11 \%$ & $36 \%$ & $25 \%$ & $6 \%$ & $36 \%$ & $31 \%$ \\
\hline West developing & $9 \%$ & $20 \%$ & $11 \%$ & $9 \%$ & $33 \%$ & $24 \%$ & $2 \%$ & $33 \%$ & $31 \%$ \\
\hline West affluent & $14 \%$ & $24 \%$ & $10 \%$ & $15 \%$ & $37 \%$ & $22 \%$ & $11 \%$ & $38 \%$ & $27 \%$ \\
\hline United States & $15 \%$ & $21 \%$ & $6 \%$ & $12 \%$ & $33 \%$ & $21 \%$ & $11 \%$ & $32 \%$ & $21 \%$ \\
\hline Global & $15 \%$ & $22 \%$ & $7 \%$ & $13 \%$ & $35 \%$ & $22 \%$ & $10 \%$ & $35 \%$ & $25 \%$ \\
\hline Women & $14 \%$ & $24 \%$ & $10 \%$ & $13 \%$ & $35 \%$ & $22 \%$ & $10 \%$ & $36 \%$ & $26 \%$ \\
\hline Men & $16 \%$ & $21 \%$ & $5 \%$ & $12 \%$ & $35 \%$ & $23 \%$ & $11 \%$ & $34 \%$ & $23 \%$ \\
\hline Women with child $<5$ & $23 \%$ & $38 \%$ & $15 \%$ & $23 \%$ & $53 \%$ & $30 \%$ & $17 \%$ & $55 \%$ & $38 \%$ \\
\hline Men with child $<5$ & $14 \%$ & $27 \%$ & $13 \%$ & $16 \%$ & $36 \%$ & $20 \%$ & $6 \%$ & $36 \%$ & $30 \%$ \\
\hline
\end{tabular}

Note. Includes employees working from 40 to $50 \mathrm{hr}$ a week. 
solute difference was for women with a child age 5 years or younger. In that group only $17 \%$ of the work-at-home, high flex reported difficulty compared to $55 \%$ of the nonwork-at-home, low-flex employees.

Break-point analyses (see Table 5) demonstrated that businesses benefit when they offer individuals work-athome flexibility as well as perceived schedule flexibility. Employees who worked primarily from home were able to work longer hours before experiencing difficulty in managing work-life demands. For example, the break point for work-at-home employees was 50 versus 46 hr/week for nonwork-at-home employees. On average, when businesses allowed an employee to chiefly work from home, the employee worked "an extra half day a week" (50 hr/week work-at-home - $46 \mathrm{hr} /$ week without work-at-home $=4 \mathrm{hr}$ more work) before reporting difficulty managing work and personal/family life. This benefit was more pronounced in some areas of the world. In the West Affluent the benefit was $8 \mathrm{hr} /$ week (50 vs. $42 \mathrm{hr}$, an extra day a week) and in the West Developing it was $16 \mathrm{hr} /$ week (61 vs. $45 \mathrm{hr}$, an extra 2 days a week). The benefits of work-at-home were clear for women with a child age 5 years and under. Their break point was 41 versus $30 \mathrm{hrs} /$ week, a benefit of $11 \mathrm{hr} /$ week. For a woman with small children who wants work-life harmony, working primarily from home meant the difference between a full-time job and three quarters-time job.

Results also suggested that perceived schedule flexibility leads to greater capacity for work hours without work-life conflict. Overall, the break point for those with high schedule flexibility was $54 \mathrm{hr} /$ week compared to 37 hr/week for those with low flexibility, a benefit of $17 \mathrm{hr}$ (more than 2 days a week). The greatest benefit was found for women with small children. With high schedule flexibility their break point was $40 \mathrm{hr} /$ week compared to the break point of $13 \mathrm{hr} /$ week for those with low schedule flexibility. Finally, when work-at-home was combined with schedule flexibility the business benefit in terms of greater work capacity was generally greater than either type of flexibility by itself. The break point for work-athome employees with high schedule flexibility was 57 hr/week compared to $38 \mathrm{hr} /$ week for nonwork-at-home employees with low schedule flexibility, a benefit of 19 hours.

\section{Discussion}

This study reveals that workplace flexibility (work-athome and perceived schedule flexibility) is generally beneficial to both individuals and businesses around the world, though cultural differences exist. Workplace flexibility reduces work-life conflict (personal/family benefit) enabling workers to work longer hours before perceiving work-life conflict (business benefit). However, all flexibility is not created equal indicated by several important themes. The first is that work-at-home should be coupled with perceived schedule flexibility to maximize benefits. Work-at-home in and of itself seems to reduce work-family conflict. However, these benefits are enhanced when work-at-home is combined with the ability to schedule one's hours to best reflect both work and personal life needs. Another theme is that the perception of schedule flexibility (availability of flexibility in the timing of work) is of greater benefit than actually using flexibility to work at home in every region of the world. This, coupled with the fact that schedule flexibility is the most valued form of flexibility by both men and women in every life stage (see Hill, Jacob, et al., 2008) makes it an attractive target for policy makers.

A final theme is the pervasiveness of these results in different groupings of countries around the world. The benefits of flexibility, at least in a high-tech professional organization, are not limited to the United States or even to developed countries. That said there appear to be cultural differences at the heart of the adaptation of flexible work arrangements and their benefits. The underlying collectivist cultural orientation may explain why, for example, the group with the lowest use of work-at-home was the group of employees from Asia $(<2 \%)$. This may reflect cultural expectations that employees with professional jobs work for long hours away from home each day to maintain solidarity with the group. Simply stated, it may be culturally unac-

Table 5

Break Point Analysis: Hours of Work Per Week at Which 25\% of Respondents Reported They Had a Difficult or Very Difficult Time Managing the Demands of Work and Personal/Family Life

\begin{tabular}{|c|c|c|c|c|c|c|c|c|c|}
\hline & \multicolumn{3}{|c|}{ Work-at-home } & \multicolumn{3}{|c|}{ Schedule flexibility } & \multicolumn{3}{|c|}{$\begin{array}{l}\text { Work-at-home and schedule } \\
\text { flexibility }\end{array}$} \\
\hline & Yes & No & $\Delta$ & High & Low & $\Delta$ & Both & Neither & $\Delta$ \\
\hline Global & 50.2 & 45.8 & 4.4 & 53.8 & 36.7 & 17.1 & 56.6 & 38.0 & 18.6 \\
\hline East & 47.7 & 43.8 & 3.9 & 53.3 & 37.3 & 16.0 & 57.8 & 37.5 & 20.3 \\
\hline West Developing & 61.4 & 45.3 & 16.1 & 55.7 & 37.5 & 18.2 & 100.3 & 37.4 & 62.6 \\
\hline West Affluent & 50.2 & 42.1 & 8.1 & 50.7 & 36.6 & 14.1 & 55.0 & 35.6 & 19.4 \\
\hline United States & 50.7 & 45.8 & 4.9 & 56.6 & 38.4 & 18.2 & 59.3 & 39.1 & 20.2 \\
\hline Global & 50.2 & 45.8 & 4.4 & 53.8 & 36.7 & 17.1 & 56.6 & 38.0 & 18.6 \\
\hline Women & 50.7 & 42.5 & 8.2 & 52.9 & 36.2 & 16.7 & 50.2 & 36.2 & 14.0 \\
\hline Men & 52.7 & 46.3 & 6.4 & 54.2 & 37.0 & 17.2 & 57.6 & 37.4 & 20.2 \\
\hline Women with child $<5$ & 41.1 & 29.6 & 11.5 & 40.3 & 13.0 & 27.3 & 66.7 & 6.9 & 59.8 \\
\hline Men with child $<5$ & 49.4 & 42.5 & 6.9 & 48.5 & 36.3 & 12.2 & 67.2 & 36.4 & 30.8 \\
\hline
\end{tabular}


ceptable to stay at home to work. This cultural expectation may also help explain why those from the East reported the most work-family conflict (see Table 2).

\section{Implications}

The findings suggest benefits to the employee as well as to the employer. Previous studies have indicated a relationship between reduced work-life conflict and reduced psychological distress, lower levels of depression and anxiety (Frone, Barnes, \& Farrell, 1994; Major, Klein, \& Ehrhart, 2002) and increased life satisfaction (Adams, King, \& King, 1996; Aryee, Fields, \& Luk, 1999). Reduced psychological distress resulting from decreased work-family conflict has also been associated with family relationships both directly and indirectly by increasing the amount of energy and psychological investment available for relationships.

These psychological benefits from work-at-home and schedule flexibility may have to do with a reduction in the time and stress associated with commuting to and from work. The daily commute now consumes an average of about 45-50 min per day in the United States (Hill, Martinengo, \& Jacob, 2007). In an inflexible work environment, the daily commute happens in periods of maximum traffic congestion and can be very stressful and time-consuming. In an environment of workplace flexibility it is possible to schedule the commute at a time other than rush hour and, thus, reduce stress and wasted time. In times of inclement weather, work-at-home may enable the employee to forgo the commute and telecommute safely from home.

Further, many jobs include periods of peak work demands. In a rigid work environment, these periods make it difficult to simultaneously meet the demands of work and family life because the work has to be done from the work location. In such times, a worker might go to the office early in the morning, eat breakfast, lunch, and dinner at the work place, and return home late at night. Workers in such conditions could go weeks with little quality personal or family time. By contrast, an employee with workplace flexibility can work the same long number of hours, but intersperse hours of quality family time each day. For example, the individual may arise early and work from home for a few hours at the beginning of the day. Then he or she could be available to prepare a family breakfast, take children to school, or get children to other care arrangements. In the evening, the flexible worker could be at home with the family during the dinner hour, and then continue work for several hours from home after the children are in bed.

Work-at-home and perceived schedule flexibility may also contribute to more quality time at work and at home. The highest quality work hours are not always between 8 a.m. and 5 p.m. The best strategic ideas may come to one at 5 a.m. or at 11 p.m. Likewise, the highest quality family time may occur during the regular work day. For example, the best time to hear about school may be right after children come home from school. Putting one's time to its best use, regardless of the hour of the day, may lead to greater work-life harmony and less conflict.
The results indicate that work-at-home and perceived schedule flexibility are particularly beneficial to parents of small children. This may result from an increased capacity for parents to overlap work time effectively with unexpected child-care situations. For example, when a child becomes ill at school, a parent in a rigid work environment would be stressed about leaving work and finding care for the sick child. Many are forced to use their vacation days or to call in sick to care for sick children. With schedule flexibility it is more likely that the parent can leave work to pick up the ill child. With work-at-home, the parent can continue to work, albeit at a reduced pace, while caring for the ill child. Knowing that one has the flexibility to care for a sick child may reduce perceptions of work-life conflict and enhance psychological well-being.

For those with responsibility to care for elders or to guide adolescents, work-at-home may be particularly beneficial. Elders and adolescents often do not require constant care, but simply someone in the same home with whom they can interact from time to time. The ability to work from home may save the expense and alleviate the logistical difficulty of arranging for adult day care. It also may provide the ability to monitor adolescents more effectively.

Work-at-home also provides more options for where an employee might choose to live, another factor related to psychological benefits. Without work-at-home, an employee has to live within commuting distance of the work location, often in or near large metropolitan areas where housing prices and other cost of living components tend to be more expensive. Work-at-home may give employees the choice to live in a small town or rural area, with a lower cost of living, a more relaxed lifestyle, and a lower crime rate (Urbanska \& Levering, 1996). These findings also have clinical implications for mental health professionals dealing with clients struggling with stress-related psychological problems. Exploring options for utilizing workplace flexibility options to reduce stress may be helpful in some situations.

Finally, the findings present evidence of organizational benefits to employers. Implementing workplace flexibility may create an environment where employees have the capacity to work longer hours before work-life conflict becomes problematic. The fact that workplace flexibility may reduce work-family conflict, and requires little or no expense to the company, makes a strong business case for its adoption. Some common workplace flexibility programs that might be considered include schedule flexibility, parttime work, job sharing, compressed work week, telecommuting, work-at-home, and the virtual office.

\section{Limitations}

Several limitations are apparent in this study. The respondents all worked for IBM. IBM employees, in general, are more highly educated, have higher salaries, and have more experience with computer technology than the general population (Hill et al., 2004). For these reasons, the degree to which these results may be generalized to other companies is uncertain. However, using a single company is not nec- 
essarily a limitation. By doing so we are able to control for the nature of the work, which would be difficult when using multiple companies.

Another concern is the nature of self-report data in a survey, especially when respondents are asked to estimate time in work activities using range of hours. Employees tend to overestimate work hours when not using a time diary approach (Robinson \& Bostrum, 1994). However, more central to this study than work hours are employees' perceptions of schedule flexibility in their work arrangements, which are appropriately measured by self-report.

\section{Conclusion}

Our results indicate that when coupled with schedule flexibility, work-at-home reduces an individual's work-life conflict, and increases his or her capacity to work, creating a win-win situation for employees and employers alike. Workplace flexibility appears to be an essential strategy for dealing with workload stress in today's uncertain global economy. If visionary policy makers and empowered individuals throughout the world adopt greater flexibility, we foresee a cycle in which workplace flexibility will promote individual well-being, family solidarity, and organizational success internationally.

\section{References}

Adams, G. A., King, L. A., \& King, D. W. (1996). Relations of job and family involvement, family social support, and work-family conflict with job and life satisfaction. Journal of Applied Psychology, 81, 411-420.

Allen, T. D., \& Shockley, K. (2009). Flexible work arrangements: Help or hype? In D. R. Crane \& E. J. Hill (Eds.), Handbook of families and work: Interdisciplinary perspectives (pp. 265-284). Lanham, MD: University Press of America.

Aryee, S., Fields, D., \& Luk, V. (1999). A cross-cultural test of a model of the work-family interface. Journal of Management, 25, 491-511. doi:10.1177/014920639902500402

Bronfenbrenner, U. (1986). Ecology of the family as a context for human development: Research perspectives. Developmental Psychology, 22, 723-742.

Byron, K. (2005). A meta-analytic review of work-family conflict and its antecedents. Journal of Vocational Behavior, 67, 169198. doi:10.1016/j.jvb.2004.08.009

Frone, M. R., Barnes, G. M., \& Farrell, M. P. (1994). Relationship of work-family conflict to substance use among employed mothers: The role of negative affect. Journal of Marriage and the Family, 56, 1019-1030.

Gajendran, R. S., \& Harrison, D. A. (2007). The good, the bad, and the unknown about telecommuting: Meta-analysis of psychological mediators and individual consequences. Journal of Applied Psychology, 97, 1524-1541. doi:10.1037/0021-9010.92.6.1524

Greenhaus, J., \& Beutell, N. (1985). Sources of conflict between work and family roles. Academy of Management Review, 10, $76-88$.

Grzywacz, J. G., Carlson, D. S., \& Shulkin, S. (2008). Schedule flexibility and stress: Linking formal flexible arrangements and perceived flexibility to employee health. Community, Work, and Family, 11, 199-214. doi:10.1080/13668800802024652

Hill, E. J., \& Civian, J. T. (Eds.). (2008). Investigating workplace flexibility using a multi-organization database: A collaboration of academics and practitioners [Special issue]. Community, Work, and Family, 11, 1-242. doi:10.1080/13668800802172576

Hill, E. J., Grzywacz, J. G., Allen, S., Blanchard, V. L., MatzCosta, C., Shulkin, S., \& Pitt-Catsouphes, M. (2008a). Defining and conceptualizing workplace flexibility. Community, Work, and Family, 11, 149-163.

Hill, E. J., Hawkins, A. J., Ferris, M., \& Weitzman, M. (2001). Finding an extra day a week: The positive effect of job flexibility on work and family life balance. Family Relations, 50, 49-58.

Hill, E. J., Jacob, J. I., Shannon, L. L., Brennan, R. T., Blanchard, V. L., \& Martinengo, G. (2008b). Exploring the relationship of workplace flexibility, gender, and life stage to family-to-work conflict, and stress and burnout. Community, Work, and Family, 11, 165-181. doi:10.1080/13668800802027564

Hill, E. J., Martinengo, G., \& Jacob, J. (2007). Working fathers: Providing and nurturing in harmony. In S. E. Brotherson \& J. M. White (Eds.), Why fathers count (pp. 279-292). Harriman, TN: Journal of Men's Studies Press.

Hill, E. J., Yang, C., Hawkins, A. J., \& Ferris, M. (2004). A cross-cultural test of the work-family interface in one corporation in 48 countries. Journal of Marriage and Family, 66, 13001316.

Hofstede, G. (1980). Culture's consequences. Beverly Hills, CA: Sage.

Hughes, E. L., \& Parkes, K. R. (2007). Work hours and well-being: The roles of work-time control and work-family interference. Work and Stress, 21, 264-278. doi:10.1080/02678370701667242

Jacob, J., Allen, S. M., Hill, E. J., \& Mead, N. L. (2008). Work interference with dinnertime as a mediator and moderator between work hours and work and family outcomes. Family and Consumer Sciences Research Journal, 36, 310-327. doi: 10.1177/1077727X08316025

Jones, B. L., Scoville, D. P., Hill, E. J., Childs, G., Leishman, J. M., \& Nally, K. S. (2008). Perceived versus used workplace flexibility in Singapore: Predicting work-family fit. Journal of Family Psychology, 22, 774-783. doi:10.1037/a0013181

Judge, T. A., Boudreau, J. W., \& Bretz, R. D., Jr. (1994). Job and life attitudes of male executives. Journal of Applied Psychology, 79, 767-782.

Major, V. S., Klein, K. J., \& Ehrhart, M. G. (2002). Work time, work interface with family, and psychological distress. Journal of Applied Psychology, 87, 427-436. doi:10.1037/00219010.87.3.427

Mesmer-Magnus, J. R., \& Viswesvaran, C. (2006). How familyfriendly work environments affect work-family conflict: A meta-analytic examination. Journal of Labor Research, 4, 555-574.

Oyserman, D., Coon, H. M., \& Kammelmeier, M. (2002). Rethinking individualism and collectivism: Evaluation of theoretical assumptions and meta-analyses. Psychological Bulletin, 128, 3-72. doi:10.1037/0033-2909.128.1.3

Robinson, J., \& Bostrum, A. (1994). The overestimated workweek? What time diary measures suggest. Monthly Labor Review, 111, 11-23.

Shockley, K. M., \& Allen, T. D. (2007). When flexibility helps: Another look at the availability of flexible work arrangements and work-family conflict. Journal of Vocational Behavior, 71, 479-493. doi:10.1016/j.jvb.2007.08.006

Urbanska, W., \& Levering, F. (1996). Moving to a small town: A guidebook for moving from urban to rural America. New York: Fireside.

Voydanoff, P. (2004). The effects of work demands and resources on work-to-family conflict and facilitation. Journal of Marriage and Family, 66, 398-412. doi:10.1016/j.jvb.2007.08.006 
Wanous, J. P., Reichers, A. E., \& Hudy, M. J. (1997). Overall job satisfaction: How good are single-item measures? Journal of Applied Psychology, 82, 247-252.

Zimmerman, M., Ruggero, C. J., Chelminski, I., Young, D., Posternak, M. A., Fiedman, M., ... Attiullah, N. (2006). Developing brief scales for use in clinical practice: The reliability and validity of single-item self-report measures of depression symptom severity, psychosocial impairment due to depression, and quality of life. Journal of Clinical Psychiatry, 67, 1536-1541.

Received June 11, 2009

Revision received February 10, 2010

Accepted February 17, 2010

\section{Members of Underrepresented Groups: Reviewers for Journal Manuscripts Wanted}

If you are interested in reviewing manuscripts for APA journals, the APA Publications and Communications Board would like to invite your participation. Manuscript reviewers are vital to the publications process. As a reviewer, you would gain valuable experience in publishing. The P\&C Board is particularly interested in encouraging members of underrepresented groups to participate more in this process.

If you are interested in reviewing manuscripts, please write APA Journals at Reviewers@apa.org. Please note the following important points:

- To be selected as a reviewer, you must have published articles in peer-reviewed journals. The experience of publishing provides a reviewer with the basis for preparing a thorough, objective review.

- To be selected, it is critical to be a regular reader of the five to six empirical journals that are most central to the area or journal for which you would like to review. Current knowledge of recently published research provides a reviewer with the knowledge base to evaluate a new submission within the context of existing research.

- To select the appropriate reviewers for each manuscript, the editor needs detailed information. Please include with your letter your vita. In the letter, please identify which APA journal(s) you are interested in, and describe your area of expertise. Be as specific as possible. For example, "social psychology" is not sufficient-you would need to specify "social cognition" or "attitude change" as well.

- Reviewing a manuscript takes time (1-4 hours per manuscript reviewed). If you are selected to review a manuscript, be prepared to invest the necessary time to evaluate the manuscript thoroughly. 